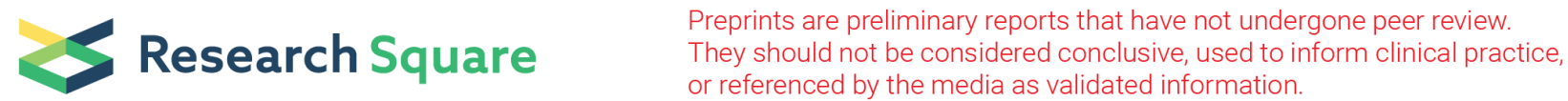

\section{Pituitary apoplexy accompanying temporal lobe epilepsy as a complication: case report}

\section{Katsunori Shijo}

Department of Neurological Surgery, Nihon University School of Medicine

\section{Sodai Yoshimura}

Department of Neurological Surgery, Nihon University School of Medicine

\section{Fumi Mori}

Department of Neurological Surgery, Nihon University School of Medicine

\section{Shun Yamamuro}

Department of Neurological Surgery, Nihon University School of Medicine

\section{Koichiro Sumi}

Department of Neurological Surgery, Nihon University School of Medicine Hideki Oshima

Department of Neurological Surgery, Nihon University School of Medicine Atsuo Yoshino ( $\square$ yoshino.atsuo@nihon-u.ac.jp)

Nihon University School of Medicine https://orcid.org/0000-0003-0673-6556

\section{Case report}

Keywords: pituitary apoplexy, pituitary adenoma, temporal lobe epilepsy, cavernous sinus, MRI

Posted Date: October 14th, 2019

DOI: https://doi.org/10.21203/rs.2.9242/v2

License: (c) (i) This work is licensed under a Creative Commons Attribution 4.0 International License. Read Full License 


\section{Abstract}

Background : Pituitary apoplexy is an acute clinical syndrome caused by infarction and/or hemorrhage of pituitary adenoma, which typically presents with severe headache, visual deterioration, and endocrine abnormalities. However, temporal lobe epileptic seizure has not been viewed as a symptom of pituitary apoplexy in the literature. Case presentation: To elucidate further such a rare complication of temporal lobe epilepsy-like seizure, we describe here the rare clinical manifestations of a 55-year-old previously healthy male with pituitary apoplexy harboring headache, combined palsies involving cranial nerves III to $\mathrm{VI}$, endocrinologic disturbances, and temporal lobe epilepsy-like seizure. In addition, we discuss the temporal lobe epilepsy associated with pituitary adenoma based on the literature. Conclusion : Although further accumulation of clinical data is needed, we would like to emphasize the importance of recognition of temporal lobe epilepsy-like seizure due to pituitary apoplexy, and to suggest that early surgery should be considered as an option in patients displaying such a rare complication.

\section{Background}

Pituitary apoplexy is a clinical syndrome that is thought to be caused by infarction, hemorrhage, or hemorrhagic infarction within a preexisting pituitary adenoma [1-4, 8-14, 17-20, 24-27]. However, pituitary apoplexy is confounded by the inclusion, in some series, of pituitary adenomas with histopathologic or radiologic evidence of hemorrhage but without sudden onset of clinical symptoms [14,27]. The classical term pituitary apoplexy presentation includes the abrupt onset of severe headache accompanied by neurologic, ophthalmologic, and/or endocrinologic deterioration due to sudden expansion of a mass within the sella turcica $[1-4,8-14,17-20,24-27]$. It is a rare event that occurs in $0.6-17 \%$ of pituitary adenomas [1-4, 8-14, 17-20, 24-27]. The most common presenting symptom is headache with a frequency varying from $63-100 \%[1-4,8-14,17-20,24-27]$. Visual abnormalities such as visual field deficit, impaired visual acuity, and/or ocular palsies may be found in $50-80 \%$ of patients $[1-4,8-14,17-20$, 24-27], due to compression of the optic chiasm and cranial nerves in the cavernous sinus. Other symptoms, such as nausea and vomiting which may be a result of headache, meningeal irritation, intracranial hypertension, and/or acute adrenal insufficiency, are found in 25 - 80\% of cases [1-4, 8-14, 1720, 24-27]. However, according to our understanding, temporal lobe epilepsy (and temporal lobe epilepsylike seizure) is not viewed as a symptom of pituitary apoplexy in the literature [1-4, 8-14, 17-20, 24-27].

To elucidate such a rare complication of temporal lobe epilepsy and epileptic seizure further, we describe here the rare clinical manifestations of a 55-year-old male with pituitary apoplexy harboring headache, ocular palsies, hypoesthesia in the second division of the trigeminal nerve, endocrinologic disturbances, and temporal lobe epilepsy-like seizure. In addition, we present a small literature review of temporal lobe epilepsy related to pituitary adenoma.

\section{Case Presentation}


A 55-year-old male was referred to our department, because computed tomography (CT) and magnetic resonance imaging (MRI) of the head undertaken at another hospital had disclosed an intra- and suprasellar abnormality. Three days prior to the CT and MRI, he had experienced slight left eye ptosis, accompanied by diplopia and retrobulbar pain. The following morning, he developed unusual headache. Prior to this event, he had been in good health. At admission, his consciousness level was clear but he demonstrated severe headache, left diplopia, eyelid ptosis, and facial numbness. On neurologic examination, restriction of lateral, medial, downward, and upward movement of the left eye was observed, and his left pupil was enlarged (approximately $5 \mathrm{~mm}$ ) and unresponsive to light. Furthermore, he experienced hypesthesia near his left cheek. However, there was no impairment of his visual acuity, and no hemianopsia. These observations indicated left oculomotor nerve, trochlear nerve, abducens nerve, and trigeminal nerve (maxillary nerve) palsies. Laboratory blood tests revealed the following: WBC count, 10,300/mm3; Hb, $14.2 \mathrm{~g} / \mathrm{dL} ; \mathrm{Ht}, 40.7 \%$; PLT count, 228,000/mm³; CRP, 8.62; Na, $133 \mathrm{mmol} / \mathrm{L} ; \mathrm{K}, 4.6$ $\mathrm{mmol} / \mathrm{L}$; and $\mathrm{Cl}, 94 \mathrm{mmol} / \mathrm{L}$. His plasma hormone levels were as follows: prolactin, $6.59 \mathrm{ng} / \mathrm{mL}$ (normal range, 3.6 - $16.3 \mathrm{ng} / \mathrm{mL})$; growth hormone, $1.70 \mathrm{ng} / \mathrm{mL}$ ( - $2.47 \mathrm{ng} / \mathrm{mL})$; insulin-like growth factor- 1,219 $\mathrm{ng} / \mathrm{mL}$ (84 - $238 \mathrm{ng} / \mathrm{mL}$ ); adrenocorticotropic hormone (ACTH), $2.7 \mathrm{pg} / \mathrm{mL}$ (7.2 - $63.3 \mathrm{pg} / \mathrm{mL}) ;$ cortisol, $1.42 \mathrm{mg} / \mathrm{dL}$ (6.24 - $18 \mathrm{ug} / \mathrm{dL})$; thyroid-stimulating hormone, $0.23 \mathrm{ulU} / \mathrm{mL}(0.34$ - $3.8 \mathrm{ulU} / \mathrm{mL})$; free T3, 2.71 $\mathrm{pg} / \mathrm{mL}(2.0-3.8 \mathrm{pg} / \mathrm{mL})$; free T4, $1.38 \mathrm{ng} / \mathrm{dL}(0.8-1.5 \mathrm{ng} / \mathrm{dL})$; luteinizing hormone, $0.8 \mathrm{mlU} / \mathrm{mL}$ (1.8 - 5.2 $\mathrm{mlU} / \mathrm{mL})$; and follicle-stimulating hormone, $2.2 \mathrm{mlU} / \mathrm{mL}(2.9-8.2 \mathrm{mlU} / \mathrm{mL})$. Based on these findings, we suspected ACTH deficiency (subsequently with reduction of corticotropin release) and gonadotropin deficiency. Replacement hormone therapy was therefore initiated with hydrocortisone.

CT and MRI of the head displayed a nonhomogenous sellar and suprasellar expansile lesion which compressed the optic chiasm indicative of pituitary apoplexy. Furthermore, this sellar mass lesion revealed significant extension into the left cavernous sinus and compression of the mesial temporal lobe, but there was absence of signs of subarachnoid hemorrhage. Diffusion-weighted and T2-weighted MRI demonstrated a markedly increased signal intensity area within the pituitary mass. Gadolinium enhanced MRI showed peripheral enhancement surrounding the pituitary mass (Figs. 1 and 2).

During informed consent, he suddenly exhibited prominent motor arrest with loss of awareness and commenced oroalimentary automatism (chewing) and gestural automatism (repetitive motor action of the right upper limb). A few minutes later, he began to experience a generalized convulsion. This was treated with intravenous administered diazepam. After this event, antiepileptic treatment (levetiracetam) was initiated.

On the day of admission to our institution, endoscopic transnasal transsphenoidal surgery was performed to remove the mass, which was soft and easy to curette. During the surgery, a low level of spinal fluid leakage was noted, but no subarachnoid hemorrhage was observed. Microscopic examinations of the surgical specimen demonstrated a large area that consisted primarily of coagulative necrosis and hemorrhage. A typical adenoma pattern forming diffuse sheets was still evident in the tumor tissues (Fig. 3). These findings were consistent with pituitary apoplexy. 
The patient was discharged from our hospital at 20 days after surgery because he was worried about the possible recurrence of epileptic seizure and hospitalization was extended based on his wishes. His postoperative course was uneventful. MRI at the time of discharge demonstrated gross total removal of the pituitary mass and no evidence of residual tumor. The diminished mass effect of the pituitary lesion resulted in improvement of the compression to the optic chiasm and mesial temporal lobe. Furthermore, MR images did not show edema and hemosiderin in the perilesional area of the temporal lobe (Fig. 4). His left oculomotor nerve deficits including eye ptosis and pupil dilatation and facial hypesthesia due to trigeminal nerve deficit gradually improved, although his abducens nerve palsy persisted after the surgery. An electroencephalogram at 20 days following surgery showed no epileptiform activity. The patient is receiving corticosteroid replacement therapy and anticonvulsant medication at his request but has had no additional epileptic seizure 8 months after surgery, and continues to be followed up.

\section{Discussion And Conclusions}

Even though several pathomechanisms have been suggested to underlie the development of spontaneous pituitary apoplexy, the true pathogenesis remains unclear [1-4, 8-14, 17-20, 24-27]. Presumably, each mechanism could contribute to the acute deterioration of an already compromised blood supply to the pituitary tumor $[4,27]$. Most cases develop spontaneously; however, several reports including our past paper [27], have suggested various conditions, procedures, and treatments that could cause pituitary apoplexy, such as diabetes mellitus, head trauma, hypertension, pregnancy, carotid angiography, lumbar puncture, myelography, pituitary function tests, pneumoencephalography, anticoagulant therapy, bromocriptine therapy, and radiotherapy [1-5, 8-14, 17-20, 24-27]. Typical pituitary apoplexy presents with severe headache, loss of vision, and endocrine abnormalities. However, we have been unable to uncover any previous reports of temporal lobe epileptic seizure occurring as a complication of pituitary apoplexy [1-4, 8-14, 17-20, 24-27].

It is easy to speculate that the pituitary adenoma, which compresses or infiltrates the inner structure of the temporal lobe due to lateral extension, can induce temporal lobe epileptic seizures. Previously, Elkington in 1968 reported that 6 cases out of 260 pituitary adenomas (2.3\%) developed epileptic seizure as a preoperative symptom; details were uncertain, but 4 of the 6 cases were of grand mal, one was of temporal lobe epilepsy, and one was of uncinate fits [6]. Deepak et al. in 2007 indicated that much of the information about pituitary adenoma-related seizures including their exact prevalence, clinical and electrophysiological characteristics, and treatment is inadequate [5]. Even now, such details remain to be fully elucidated.

Epileptic seizures have been observed as a complication of medically treated prolactin-producing macroadenoma. Niwa et al. (Japanese-language paper) reported that treatment with bromocriptine alone for prolactin-producing macroadenomas with lateral extension to the cavernous sinus revealed symptomatic seizures during the medical course in 3 out of 9 cases, although in all cases a rapid decrease of serum prolactin level was recognized and in 8 cases evidence of tumor shrinkage was found on CT and/or MRI. Additionally, a hypointense signal on both T1- and T2-weighted images, consistent 
with hemosiderin due to intratumoral hemorrhage caused by bromocriptine, was recognized around the residual tumor in 3 cases with seizure. They suggested therefore that hemosiderin deposition within the medial surface of the temporal lobe, following bromocriptine therapy for prolactin-producing macroadenomas with intradural supracavernous extension, could be a trigger of such seizures [16]. Thus, if the hemosiderin remains within the adenoma, no seizures will occur, but if the hemosiderin escapes from the adenoma and comes into contact with the medial aspect of the temporal lobe, it could trigger a seizure attack. Deepak et al. reported that 6 out of 29 patients ( 5 cases of temporal lobe epilepsy and one presenting with grand mal seizure), diagnosed as having macroprolactinoma, which invades the brain parenchyma, had a history of epilepsy prior to or at pituitary adenoma presentation. However, the remaining 23 patients showed no clinical symptoms suggesting epileptic activity despite the presence of brain infiltration by the adenoma on neuroimaging. All 5 patients with temporal epilepsy experienced an immediate reduction in the occurrence of seizures following initiation of dopamine agonist treatment, which coincided with the fall in their serum prolactin levels but with minimal or no radiologic change in the appearance of their tumors, and additionally it was possible to reduce their dose of anti-epileptic medication due to the anti-epileptogenic function of dopamine agonist [5]. On the other hand, gamma knife surgery can serve as a therapeutic tool for uncontrolled pituitary adenoma, but radiation induced MR changes outside of the radiosurgical target and associated transient increases of seizure rate are well-known side effects of radiosurgery [21]. Schindler et al. reported the first case of radiation-induced changes to the mesial temporal lobe structures and transient symptomatic epileptic seizures as rare side-effects of gamma knife radiosurgery of the cavernous sinus in residual growth hormone secreting pituitary adenoma. The MR changes of their patient were temporary and a diffuse hyperintensity lesion on T2-weighted images with central enhancement was noted in the medial temporal lobe [21]. In our case, it is inferred that unusual compression (including brain edema due to compression of the parenchyma) elicited temporal lobe epilepsy-like seizure, since no changes have been noted in temporal lobe images. However, follow-up with future imaging, such as of the appearance of hemosiderin deposition within the medial surface of the temporal lobe and/or changes to the mesial temporal lobe structures, will be needed to confirm the epileptogenicity and to predict future seizures in our case.

There is as yet no clear consensus regarding the best option for the management of pituitary apoplexy [14, 7-14, 17-20, 23-28]. However, classical pituitary apoplexy represents one of the major medical emergencies, and there is no doubt that immediate fluid administration and replacement with hydrocortisone to achieve hemodynamic stability and to reduce hormone deficiencies are important for saving lives [1-4, 7-14, 17-20, 24-27]. On the other hand, the role of pituitary surgery and the timing of surgical decompression of the pituitary fossa remain topics of debate [1-4, 7-14, 17-20, 24-28]. Hitherto, it has been widely accepted that transsphenoidal surgery can be minimally invasive within the first week and should be considered in the presence of severe visual loss for pituitary apoplexy, and that patients without severe visual loss or consciousness impairment may be treated expectantly by conservative management [1-4, 7-14, 17-20, 23-28]. Temporal lobe epilepsy-like seizure induced by pituitary apoplexy is a rare symptom, and it has not been viewed as a complication in the literature [1-4, 8-14, 17-20, 24-27]. 
However, recognition and optimal treatment of temporal lobe epilepsy-like seizure as a complication of pituitary apoplexy are important, because patients with epilepsy exhibit a diminished quality of life and a high mortality rate as compared to the general population [21, 22], and patients with temporal lobe epilepsy are frequently resistant to anti-epileptic medication $[15,22]$. On the other hand, involvement of epileptogenicity over the time course, e.g. irreversible changes within the temporal lobe due to continuous compression and hemosiderin deposition, should be eliminated. Thus, although further accumulation of clinical data is needed, we would like to suggest that early surgery should be considered as an option in patients with temporal lobe epilepsy-like seizure occurring as a complication of pituitary apoplexy.

\section{Abbreviations}

CT: computed tomography; MRI: magnetic resonance imaging; WBC: white blood cell; Hb: hemoglobin; Ht: hematocrit; PLT: platelet; CRP: carbon reactive protein; Na: sodium; K: potassium; Cl: chlorine; ACTH: adrenocorticotropic hormone.

\section{Declarations}

\section{Ethics approval and consent to participate}

Not applicable.

\section{Consent for publication}

The patient and next of kin have consented to submission of the case report for journal publication, and we have obtained written informed consent.

\section{Availability of data and materials}

All data related to this case report are contained within the manuscript.

\section{Competing interests}

All authors have no affiliations with or involvement in any organization or entity with any financial interest, or non-financial interest, in the subject matter or materials discussed in this case report.

\section{Funding}

None of the authors have received any financial assistance related to this manuscript.

\section{Authors' contributions}

KSh and AY contributed to the concept of the manuscript and drafted the manuscript. HO and SYa revised the manuscript and contributed to the concept of the manuscript. SYo, FM, and KSu contributed 
to the obtainment and interpretation of the clinical information. All authors have read and approved the final version of the manuscript.

\section{Acknowledgements}

Not applicable.

\section{References}

1. Abbara A, Clarke S, Eng PC, Milburn J, Joshi D, Comninos AN, Ramli R, Mehta A, Jones B, Wernig F, Nair R, Mendoza N, Sam AH, Hatfield E, Meeran K, Dhillo WS, Martin NM (2018) Clinical and biochemical characteristics of patients presenting with pituitary apoplexy. Endocr Connect 7: 10581066

2. Albani A, Ferraù F, Angileri FF, Esposito F, Granata F, Ferreri F, Cannavò S (2016) Multidisciplinary management of pituitary apoplexy. Int J Endocrinol 2016: 7951536

3. Briet C, Salenave S, Bonneville JF, Laws ER, Chanson P (2015) Pituitary apoplexy. Endocr Rev 36: 622-645

4. Cardoso ER, Peterson EW (1984) Pituitary apoplexy: a review. Neurosurgery 14: 363-373

5. Deepak D, Daousi C, Javadpour M, MacFarlane IA (2007) Macroprolactinomas and epilepsy. Clin Endocrinol (Oxf) 66: 503-507

6. Elkington SG (1968) Pituitary adenoma: preoperative symptomatology in a series of 260 patients. $\mathrm{Br}$ J Ophthalmol 52: 322-328

7. Fan Y, Bao X, Wang R (2018) Conservative treatment cures an elderly pituitary apoplexy patient with oculomotor paralysis and optic nerve compression: a case report and systematic review of the literature. Clin Interv Aging 13: 1981-1985

8. Giammattei L, Mantovani G, Carrabba G, Ferrero S, Di Cristofori A, Verrua E, Guastella C, Pignataro L, Rampini P, Minichiello M, Locatelli M (2016) Pituitary apoplexy: considerations on a single center experience and review of the literature. J Endocrinol Invest 39: 739-746

9. Giritharan S, Gnanalingham K, Kearney T (2016) Pituitary apoplexy: bespoke patient management allows good clinical outcome. Clin Endocrinol (Oxf) 85: 415-422

10. Glezer A, Bronstein MD (2015) Pituitary apoplexy: pathophysiology, diagnosis and management. Arch Endocrinol Metab $₫ 59:$ 259-264

11. Grzywotz A, Kleist B, Möller LC, Hans VH, Göricke S, Sure U, Müller O, Kreitschmann-Andermahr I (2017) Pituitary apoplexy: a single center retrospective study from the neurosurgical perspective and review of the literature. Clin Neurol Neurosurg 163: 39-45

12. Hage R, Eshraghi SR, Oyesiku NM, loachimescu AG, Newman NJ, Biousse V, Bruce BB (2016) Third, fourth, and sixth cranial nerve palsies in pituitary apoplexy. World Neurosurg 94: 447-452

13. Kerr JM, Wierman ME (2011) Pituitary apoplexy. BMJ 342: d1270 
14. Kleinschmidt-Demasters BK, Lillehei KO (1998) Pathological correlates of pituitary adenomas presenting with apoplexy. Hum Pathol 29: 1255-1265

15. Kwan P, Brodie MJ (2000) Early identification of refractory epilepsy. New England J Med 342: 314319

16. Niwa J, Tanabe S, Hashi K (1996) Seizures as a late complication of bromocriptine therapy in patients with prolactin-producing macroadenomas: correlation between lateral extension of the adenoma and seizure onset. No Shinkei Geka 24: 913-919

17. Pyrgelis ES, Mavridis I, Meliou M (2018) Presenting symptoms of pituitary apoplexy. J Neurol Surg A Cent Eur Neurosurg 79: 52-59

18. Rajasekaran S, Vanderpump M, Baldeweg S, Drake W, Reddy N, Lanyon M, Markey A, Plant G, Powell M, Sinha S, Wass J (2011) UK guidelines for the management of pituitary apoplexy. Clin Endocrinol (Oxf) 74: 9-20

19. Randeva HS, Schoebel J, Byrne J, Esiri M, Adams CB, Wass JA (1999) Classical pituitary apoplexy: clinical features, management and outcome. Clin Endocrinol 51: 181-188

20. Ricciuti R, Nocchi N, Arnaldi G, Polonara G, Luzi M (2018) Pituitary adenoma apoplexy: review of personal series. Asian J Neurosurg 13: 560-564

21. Schindler K, Christ ER, Mindermann T, Wieser HG (2006) Transient MR changes and symptomatic epilepsy following gamma knife treatment of a residual GH-secreting pituitary adenoma in the cavernous sinus. Acta Neurochir (Wien) 148: 903-908

22. Tomson T, Beghi E, Sundqvist A, Johannessen SI (2004) Medical risks in epilepsy: a review with focus on physical injuries, mortality, traffic accidents and their prevention. Epilepsy Res 60: 1-16

23. Tu M, Lu Q, Zhu P, Zheng W (2016) Surgical versus non-surgical treatment for pituitary apoplexy: a systematic review and meta-analysis. J Neurol Sci 370: 258-262

24. Turgut M, Ozsunar Y, Başak S, Güney E, Kir E, Meteoğlu I (2010) Pituitary apoplexy: an overview of 186 cases published during the last century. Acta Neurochir (Wien) 152: 749-761

25. Vicente A, Lecumberri B, Gálvez MÁ; Grupo de Trabajo de Neuroendocrinología (2013) Clinical practice guideline for the diagnosis and treatment of pituitary apoplexy. Endocrinol Nutr 60:582.e1582.e12

26. Wildemberg LE, Glezer A, Bronstein MD, Gadelha MR (2018) Apoplexy in nonfunctioning pituitary adenomas. Pituitary 21: 138-144

27. Yoshino A, Katayama Y, Watanabe T, Ogino A, Ohta T, Komine C, Yokoyama T, Fukushima T, Hirota H (2007) Apoplexy accompanying pituitary adenoma as a complication of preoperative anterior pituitary function test. Acta Neurochir (Wien) 149: 557-565

28. Zhan R, Li X, Li X (2016) Endoscopic endonasal transsphenoidal approach for apoplectic pituitary tumor: surgical outcomes and complications in 45 patients. J Neurol Surg B Skull Base 77: 54-60

\section{Figures}




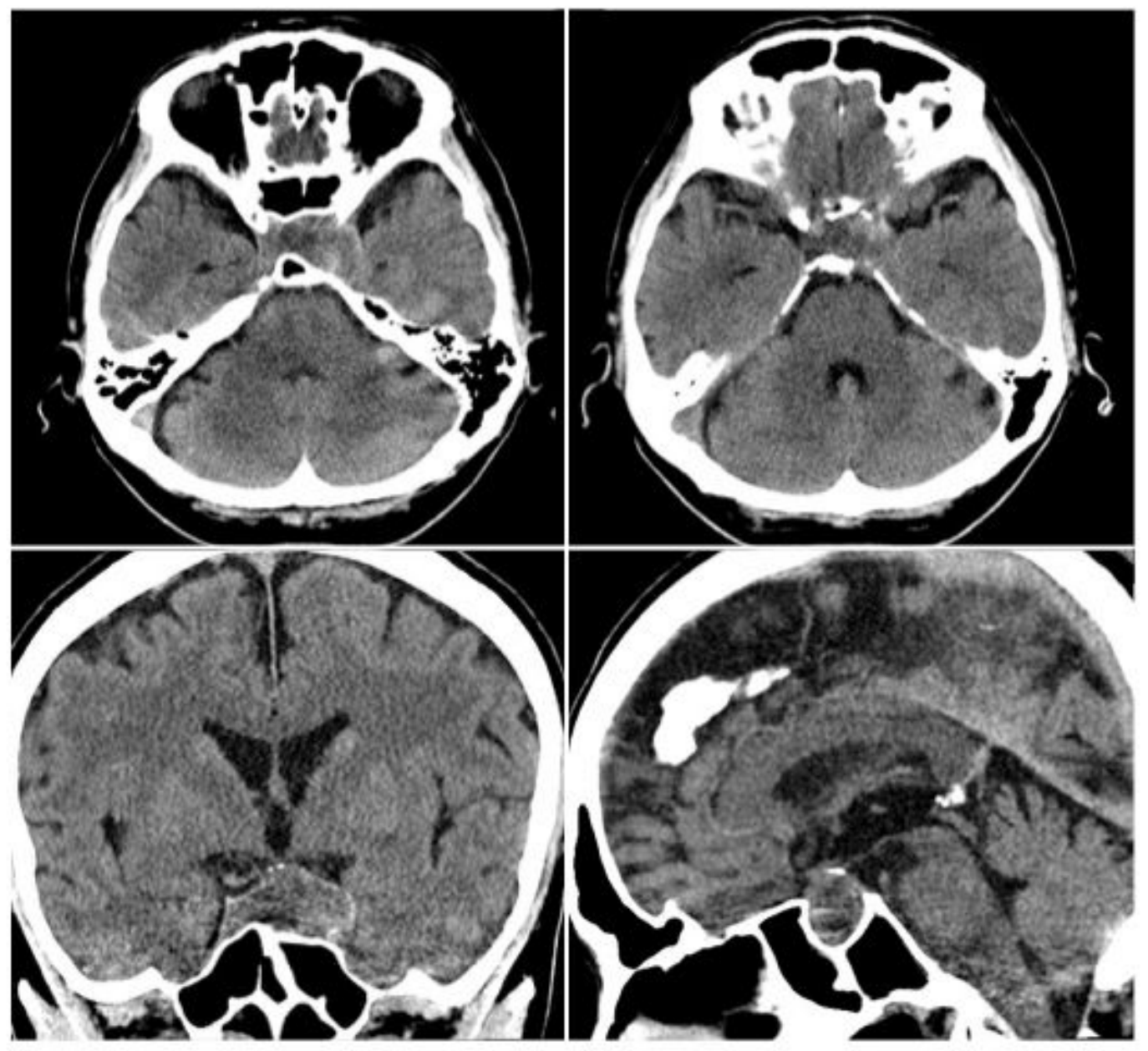

Figure 1

Plain computed tomography (CT) of the head disclosing an enlarged sellar mass lesion with a partially slight high density, but no evidence of subarachnoid hemorrhage 

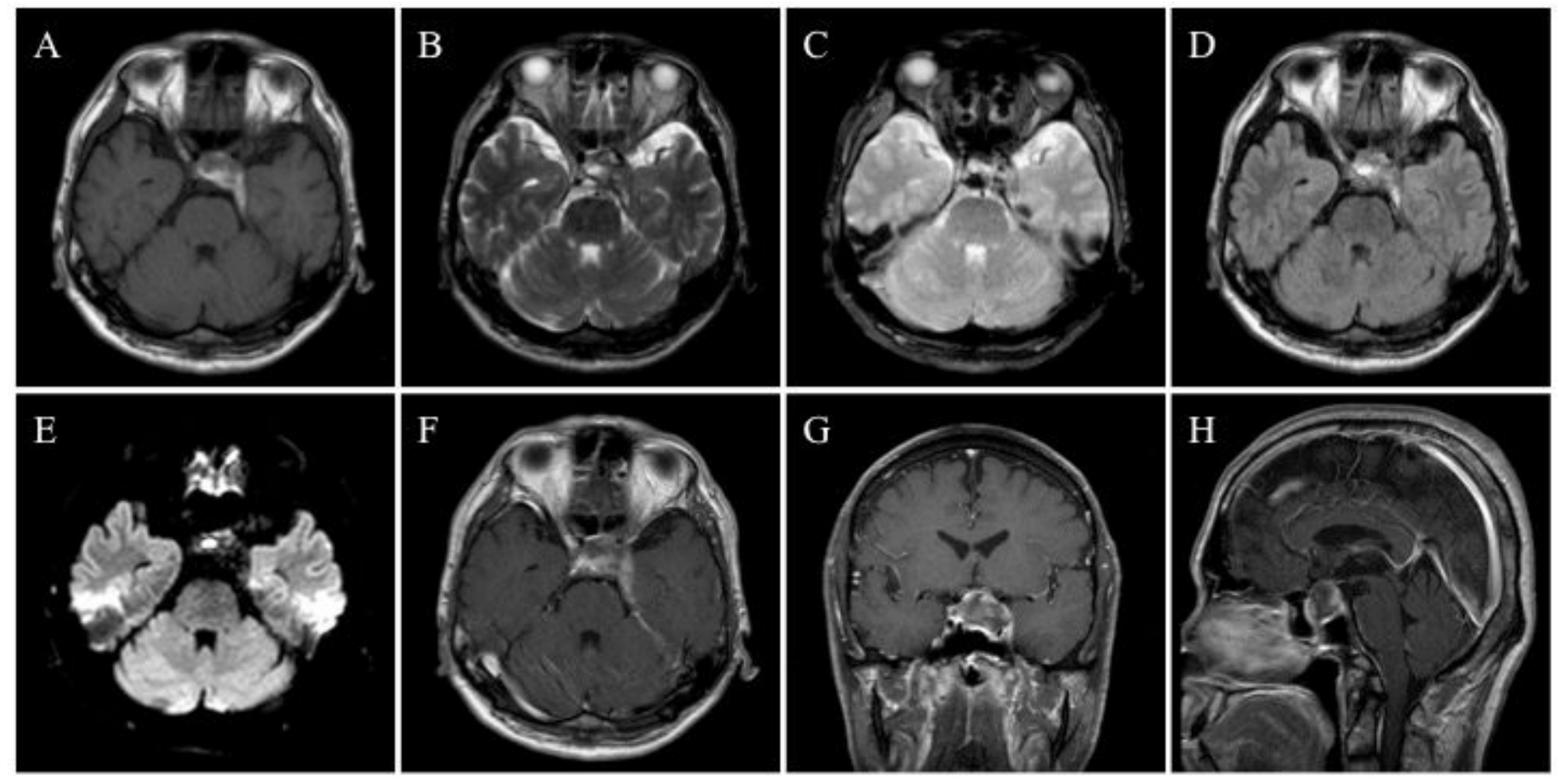

\section{Figure 2}

Magnetic resonance imaging (MRI) revealing a nonhomogenous mass filling the sella with extension into the suprasellar region and entering the left cavernous sinus. The images show axial T1-weighted (A), T2weighted (B), T2*-weighted (C), fluid-attenuated inversion recovery (FLAIR) (D), and diffusion-weighted (E) MRI. Furthermore, gadolinium enhanced T1-weighted axial ( $F)$, coronal $(G)$, and sagittal $(H)$ MRI demonstrated peripheral enhancement surrounding the pituitary mass lesion, attachment to the optic chiasm, and a compressed mesial temporal lobe. 


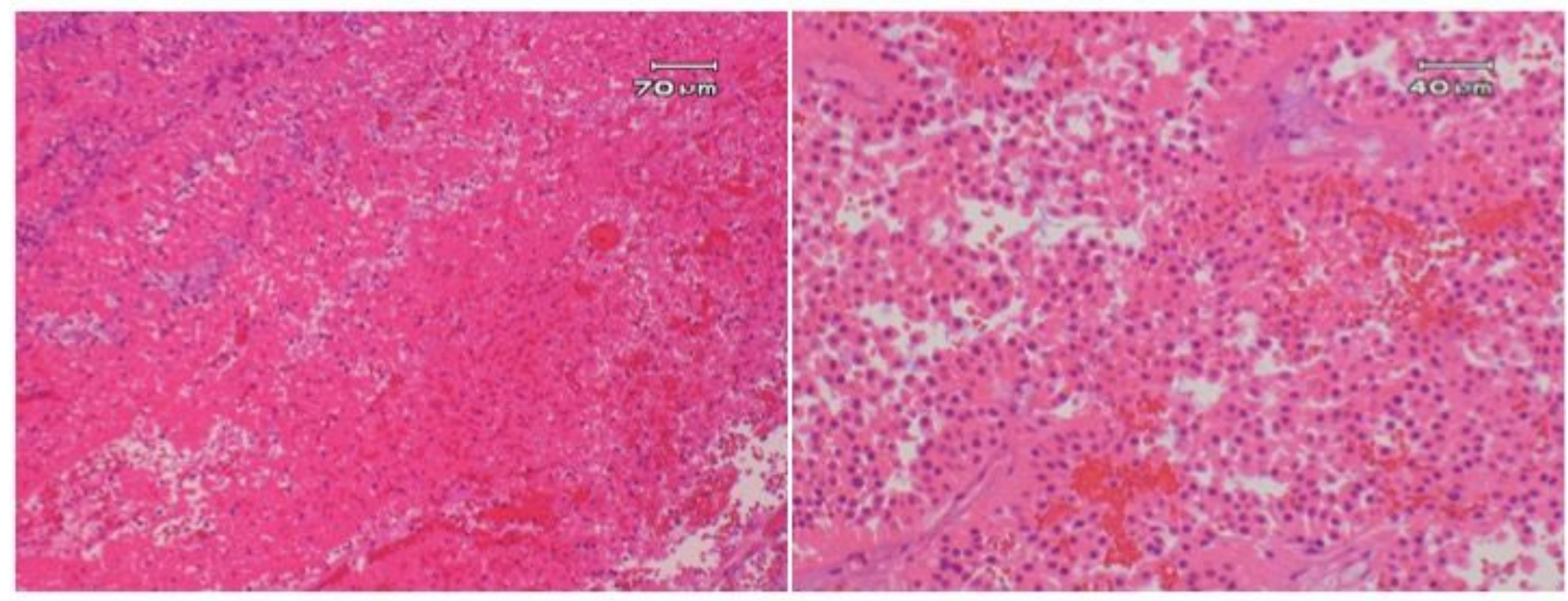

\section{Figure 3}

Histological examinations of the surgical specimen revealed large areas that had recently been almost totally infarcted (left: low magnification image, hematoxylin and eosin staining). A typical adenoma pattern, which was eosinophilic, of high cellularity, and formed diffuse sheets, was still demonstrated in the residual tumor tissues (right: high magnification image). 

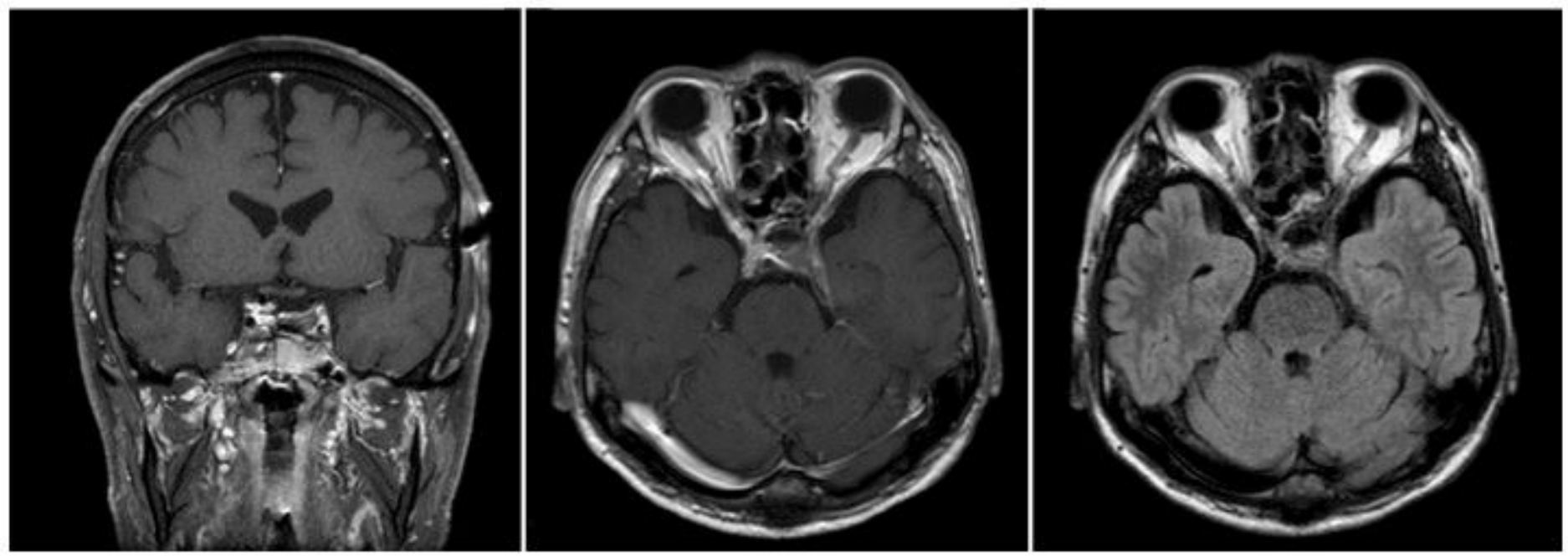

Figure 4

Immediate post-operative MRI demonstrating removal of the sellar mass including part of left cavernous sinus. Gadolinium enhanced T1-weighted coronal (A), axial (A), and FLAIR (C) MRI showed no attachment to the optic chiasm and no compression of the mesial temporal lobe.

\section{Supplementary Files}

This is a list of supplementary files associated with this preprint. Click to download.

- CAREChecklistofacasereport20190902.pdf 